\title{
Using Text Analysis to Assess Qualitative Student Works, Deal With INTER- RATER Reliability, ANd Simultaneously COMPLY WITH AACSB STANDARD 8 and Middle States Standard V
}

\author{
Guy H. Gessner and Karen M. Kutt-Doner
}

A web appendix for this paper is available at:

http://dx.doi.org/10.15239/j.brcacadje.2016.05.01.wa03

Guy Gessner is corresponding author.

Guy H. Gessner Ph.D.

Associate Professor of Marketing

Department of Marketing and Information Systems

Canisius College

2001 Main St., Buffalo, NY 14208.

Email: Gessner@canisius.edu.

Telephone: (716) 888-2639.

Karen M. Dutt-Doner, Ph.D.

Professor of Teacher Education

Canisius College

2001 Main St., Buffalo, NY 14208.

Email:duttdonk@canisius.edu. 
54 The BRC Academy Journal of Education Vol. 5, No. 1

Telephone: 716-888-2596

\begin{abstract}
The purpose of this research is to determine if the analytical process of text analysis or text mining can be adapted successfully as a tool to help automate assessment of student works related to ways in which they demonstrate progress in meeting institutional and accreditation standards. Student works in this case are assignments from graduate and undergraduate courses in business. An electronic library with six dictionaries was built containing Jesuit and Catholic keywords, phrases, concepts and synonyms so text analysis has the ability to identify these institutional learning goals within student work products. Conclusions from this study are that text mining can be adapted successfully as an automated solution for assessing large volumes of student works without involvement of large numbers of assessors and therefore without the problem of inter-rater reliability that comes from using multiple human assessors.
\end{abstract}

Keywords: text mining, text analysis, assessment, faith-based, institutional learning objectives, libraries

\title{
INTRODUCTION
}

Assessing a large number of qualitative student work products for higherlevel learning is often a challenge for faculty members. The challenge comes when these student work products are unstructured or open-ended like short answers, essays and papers. When students create original answers they will use different words with similar meanings, different logic to present the knowledge they have acquired, and communicate what they have learned in different sequences. The variation between student work products is what makes assessment of qualitative work difficult, the volume of student work products that needs to be assessed to be representative of the population of students is what makes it laborious, 
and the use of multiple human assessors can make a manual assessment process unreliable.

It can be difficult for students to communicate their depth of understanding of more complex topics and problems unless they are given the freedom to create their own work products. Structured response formats such as true or false questions, or multiple choice questions, constrain student responses to a process of selecting from among the responses created and communicated by someone else that is assumed to be an expert on the topic. Explicit within these fixed-format response forms is that there is a correct answer, even if it is 'none of the above'. With these assessment instruments students need not think about the knowledge that needs to be communicated nor display the skills necessary to communicate effectively, they only need to focus their attention on how to identify and select among answers that were already composed and communicated by experts.

Unstructured response formats require students to create and communicate a body of organized thought, there are no answers provided by experts to select from in front of them. In unstructured response formats students need to demonstrate they possess the communication skills necessary to convey they have achieved a level of understanding about a topic. More complex topics and challenges often do not have a single correct answer or perhaps is a correct answer even known. For example, an instructor can ask students to construct a response to the question: What is the solution for providing health care to a large population? The correct answer is perhaps unknown, but a credible answer would demonstrate knowledge of the topic, an understanding of the complexities and trade-offs, an analysis and evaluation of other efforts, and skill in creation of communications of a well-reasoned solution. A credible answer would cover much of the range of recognized learning taxonomies such as a revised Bloom's Taxonomy (Center for Excellence in Learning and Teaching). 
Even with common rubrics, semantic pattern recognition appears to be at the heart of the challenge. Using a rubric and a manual process of reading and decoding student works, in an effort to recognize key-words and concepts, is extremely laborious and very subjective especially when different semantic structures are presented by different students and assessment is conducted by different assessors. If a manual process using rubrics is applied to large numbers of students, several assessors will be needed creating the conditions for questionable interrater reliability. This paper examines a more automated solution for help with assessing unstructured student work products. The result is a more reliable, transparent, and efficient process for assessment of unstructured student work products.

Automating the process of recognizing semantic patterns in the form of single words or phrases is the reason natural language processors were developed. The use of Natural Language Processors (NLP) on sets of words and phrases is often commonly called 'text-mining' or text analysis. A major advantage of using a NLP as an assessment tool is that it has the ability to recognize different semantic structures that have the same meaning.

\section{Text Analysis of Student Work Products}

Text analysis (text mining) is the process of extracting meaning from text. The problem with text is that it is considered unstructured and more ambiguous than numeric data. Different words and sequences of words can have different meanings. The unambiguous properties associated with numeric data are missing from text. Organizing unstructured data is part of the challenge: assigning unambiguous interpretation and meaning is at quite another level of difficulty. The meaning within different blocks of text needs to be determined in advance by analysts preparing to use text analysis software. Users of text analysis software need to first answer the question, what are we searching for? Assessing qualitative student work products is the search for specific content indicative of student 
possession of specific knowledge or skills as stated in learning goals and objectives. This directed search requires that student work products be compared to a standard or template that determines the extent to which the searched for knowledge or skills are present or absent. In the manual process the template is called a rubric and the rubric requires the support of human intervention to judge if the submitted student work products possess the same content and meaning as the rubric. Text analysis performed in this research paper deployed a computerized natural language processor as the assessor and a library and set of dictionaries as the rubric. (IBM SPSS, 2010)

Text analysis is finding broad commercial applications but is still finding limited use in educational research $(\mathrm{Yu}, 2009)$ although it appears that interest in its use is growing (Yu, Jannasch-Pennell, Digangi , 2011). Two recently published papers highlight the use of IBM SPSS Text Analytics for Surveys, the software used in this study, for use in their efforts to assess student written works. Xu and Reynolds (Xu \& Reynolds, 2012) applied this software for assessing student written work in their study of teacher leadership. They found significant correlations between assessments conducted manually and by using text analytics. They also discovered that the accuracy of their automated assessments depended upon the natural language libraries that are available. Kaplan, Haudek, Ha, Rogness, and Fisher (Kaplan, Haudek, Ha, Rogness, \& Fisher, 2014) compared two different software packages in their ability to help them assess undergraduate written student work. One of the software packages included in their research was IBM SPSS Text Analysis for Surveys, version 4.0. They achieved good results but concluded that both software products required a degree of analyst involvement in the process. For the IBM product involvement was needed in the areas of development of categorization rules and libraries. They also go on to state that one of the benefits of the IBM product is the ability of analysts to create libraries and classification rules. This ability to readily adapt the IBM software product for different applications is one reason the product was selected for use in this study. 
A pragmatic reason to look at text mining as a tool to help with assessment of student work products was provided by Kelley, Tong, and Choi (2010). Their research indicates that the amount of time assessment takes was a major concern of faculty. That finding was not a surprise given that over $90 \%$ of their survey respondents indicated that they used written assignments for assessment.

The emerging backbone for text analysis is Natural Language Processing (NLP). NLP is the next step in the evolution from counting words to syntactic representation of text (Cambria and White, 2014). NLP helps to remove some ambiguity in meaning (word-sense disambiguation), multiple meanings of words and phrases that need to be put into context to be understood (textual entailment), and identification of the arguments associated with verbs (shallow semantic parsing). Cambria and White (2014) provide a comprehensive overview of the evolution and future of natural language processing.

This study employs some of the natural language processing capabilities provided by IBM in their software package SPSS Text Analytics for Surveys, version 4.0. An additional library and associated dictionaries are added to the base content to tailor the analysis to this specific application. This research does not evaluate the software; it simply uses it as a platform for assessment of qualitative student responses.

\section{Assessment of Faith-Oriented Institutional Learning ObJectives}

Of importance to many institutions is the development of assessment tools that help determine if students are meeting institutional learning goals. Assignments that incorporate elements of institutional learning goals and rubrics that systematically evaluate students' work against these goals provide meaningful data. As a Jesuit college, some institutional learning goals focus on knowledge, skills, and connection to Jesuit mission and identity. The assignment utilized and reported in this study, 
systematically engaged students in considering elements of Catholic and, more specifically, Jesuit ideals in creating their response to the task.

\section{Embedded Student Assignment: Compose an Appeal}

Students in two different online courses in global logistics were given an assignment on providing logistics support for humanitarian relief efforts. This assignment was created by one of the authors. One set of students were enrolled in a graduate business program and the other set of students were enrolled in a senior-level undergraduate course for business majors. As the first part of the assignment students in both courses were asked to compose a message of no more than 250 words to their fictitious global logistics companies asking them to support a request by Catholic Relief Services (CRS) to provide logistics support. Graduate business students were given a choice to provide logistics support to humanitarian relief efforts to the city and region around Akobo in South Sudan or the region and city of Bossangoa in the Central African Republic. Undergraduate students were to provide humanitarian relief to Jimma Ethiopia where a major university is located.

The instructions given to MBA students by the instructor were:

"From your reflection you conclude it is important for your company to get involved. As a first step you need to draft a clear and compelling message that appeals to all 1,000 of your employees and your Board of Directors that motivates them to support involvement by your company. This message needs to reinforce the values of your company and their fit with CRS. It needs to be short, 250 words or less."

Similar instructions were given to the course of undergraduate students:

"From your reflection you conclude it is important for your company to get involved. As a first step you need to draft a clear and compelling message that appeals to your fellow employees and the Board of Directors of the company that motivates them to support involvement 
by your company. This message needs to reinforce the values of your company and their fit with CRS. It needs to be short, 250 words or less."

In addition to their previous course work which they could reflect on, students were asked to review the following five reference materials to reflect upon when composing their message:

1. A list of 17 quotes on poverty and hunger from Catholic Social Teaching provided found on the web site of Catholic Relief Services(Catholic Relief Services).

2. A video message from Pope Francis announcing the Global Campaign against Hunger (Catholic Relief Services)

3. A video message from Pope Francis regarding hunger (Catholic Relief Services)

4. A video on the Allegory of the Long Spoons (Catholic Relief Services)

5. Catholic Relief Services web site (Catholic Relief Services)

Both graduate and undergraduate students were given the institutional learning goals and objectives associated with this assignment: (Canisius College)

\section{A. Academic Excellence - Knowledge}

- Students demonstrate an awareness of the many perspectives that inform human experiences and understand the responsibilities of a global citizen in the modern world.

- Students demonstrate a general knowledge of ethical and moral issues as well as ones specific to their fields of study.

\section{B. Catholic \& Jesuit Mission \& Identity}

- Students demonstrate a familiarity with dimensions of the Catholic and Jesuit intellectual traditions as they occur in literature, art, science and social teaching. 
- In the Jesuit tradition, be intentional learners who can adapt to new environments, integrate knowledge, and continue learning throughout their lives.

- Use their gifts for the service of others and the benefit of society.

\section{ASSESSMENT OF INTERRELATED LEARNing GoAls is REQUIRED}

Most schools of business in the U.S. do not stand alone but are part of a larger educational institution. The larger educational institution is usually reviewed for accreditation by a regional accreditor that reports to the U.S. Department of Education. Middle States Commission on Higher Education is the regional accreditor for this academic institution and AACSB has accredited this business school at both undergraduate and graduate levels. It is accreditation by regional accreditors, approved by the U.S. Department of Education such as Middle States that enables students to borrow money from the U.S. Federal Government to pay for tuition so maintaining accreditation from a regional competitor can be critical for the financial stability of any institution of higher education. Accreditation Standard V by the Middle States Commission on Higher education could be interpreted as desiring a connection between the learning goals of the institution at large and each of the programs it offers. Standard V: Educational Effectiveness Assessment (Middle States Commission on Higher Education, 2015) specifically states:

1. "clearly stated educational goals at the institution and degree/ program levels, which are

a. interrelated with one another..."

2. "organized and systematic assessments, conducted by faculty and/ or appropriate professionals, evaluating the extent of student achievement of institutional and degree/program goals.” (p. 10).

Standard V from Middle States Commission on Higher Education appears to require that educational institutions need to be able to demon- 
strate that institutional educational goals and degree/program learning goals are interrelated. They appear to be requiring linkage between the institution and the each degree or program. This paper selected the institutional learning goals of Academic Excellence - Knowledge and Catholic \& Jesuit Mission \& Identity to assess to see if students in the business program can demonstrate knowledge and/or skill in the application of these areas of learning. But there is also another reason driven by AACSB accreditation requirements (AACSB, 2015).

One basis used for judging if a business school has met AACSB Standard 8 is if "learning goals derive from and are consonant with the school's mission, expected outcomes, and strategies" (p. 30). The mission statement for this School of Business contains three relevant statements that pertain to the work product students were asked to submit:

1. School develops business professionals to lead within organizations

2. Behave as ethically and socially responsible individuals

3. Needs to accomplish this in the Jesuit tradition.

There are specific learning goals and objectives for both the undergraduate and graduate programs in business pertaining to ethical leadership, social responsibility, and knowledge of ethical frameworks for managerial decision making. The desire for students to be knowledgeable in Jesuit traditions of leadership, and service for others link together the institutional learning goals selected for this research, the mission of this school of business and select learning goals and objectives for the undergraduate and graduate programs of this school of business. The mission of this School of Business and some of the program learning goals and objectives appear to be aligned with some of the Jesuit-oriented institutional learning goals and objectives as desired by both Middle States Commission on Higher Education and AACSB. 


\section{Subset of Learning Objectives Analyzed}

Some of the learning objectives as stated contain multiple objectives that needed to be assessed separately. Toward that end the authors selected the following subset of learning objectives to assess in this research study:

1. Students demonstrate knowledge of the human experience. (Academic Excellence - Knowledge)

2. Students demonstrate knowledge of the responsibilities of global citizenship (Academic Excellence - Knowledge)

3. Students demonstrate knowledge of ethical and moral issues (Academic Excellence - Knowledge)

4. Students demonstrate familiarity with dimensions of Catholic Social Teaching (Catholic \& Jesuit Mission \& Identity)

5. Students advocate using their gifts for the service of others and the benefit society (Catholic \& Jesuit Mission \& Identity)

\section{Set-Up for Text Analysis}

The major task in preparation for text analysis is constructing the semantic patterns that contain the words and phrases that characterize knowledge of specific learning objectives. These topic-specific libraries and dictionaries can then be used in the analysis of the student works. In data mining what is matched are data patterns, in text mining it is semantic patterns that are matched. Semantic patterns can be thought of as patterns of letters which form words, and patterns of words to form phrases. When the 'jargon' of terms and phrases associated with specific applications are not part of the everyday language used by the majority of the population, special dictionaries need to be built containing these terms. These sets of dictionaries that represent unique applications can be placed into libraries containing the terms grouped into dictionaries by topic or theme. For this research project a new library and set of 
dictionaries was created to contain terms and phrases that were expected to be found within the student work products that were assessed.

In order to develop a dictionary that can be utilized effectively in the assessment of student work, careful reflection needs to take place. The goals and learning objectives need to be carefully considered and clear terms need to be identified by assessors that would indicate the student's work demonstrates proficiency in meeting them. In order for the text mining process to be effective, dictionaries need to be comprehensive and inclusive of all possible responses that can be identified in student works that would indicate knowledge, skills or dispositions related to the learning goals.

A library called Poverty and Hunger, and six dictionaries were built for this specific application by the authors to provide some of the terms, phrases and semantic meanings needed to determine if students were providing evidence of their level of knowledge of specific learning objectives. The terms, phrases and semantic meanings created in the Poverty and Hunger library are found in references the students were directed to review for the assignment. Semantic meanings are assigned to terms and phrases using the strategy for creating the dictionaries. Different sets of words and phrases that were deemed to have the same meanings were declared as synonyms in the dictionary of synonyms. For example, the authors created a dictionary called Negative Behaviors. The word 'Negative' in the title is the semantic meaning; all terms and phrases in this dictionary are meant to be negative and this must be indicated in the dictionary. The word 'Behaviors' in the title suggests that the terms that will be found in this dictionary represent human behaviors. In our application the human behavior of acquiring superfluous wealth is considered a negative behavior. The phrase superfluous wealth is found within a quote from Pope Paul VI in the set of quotes on Poverty and Hunger from Catholic Social Teaching provided by Catholic Relief Services (Catholic Relief Services). Also created were a number of synonyms to help control for misspellings (poverty and povery are both 
assigned the correct spelling of poverty) and to limit the number of terms that would have the same meaning for this particular application. For example a term 'Right to Life' was created as a term with the synonyms: right to food, right to clothing, right to shelter, right to medical care and right to rest. When the software finds any of the synonyms in the student work product, it displays 'Right to Life' as the term extracted. Figure 1 displays the library and associated dictionaries created for use in this specific application.

It is through the documented process of library development with its associated dictionaries that the core problem of inter-rater reliability which is a concern with assessment of qualitative work by multiple humans is ameliorated. Yu, Jannasch-Pennell, and DiGangi (2011) discuss how text analysis using natural language processing improves consistency and replicability which help to deal with inter-rater reliability concerns characteristic of evaluations of qualitative works.

\section{Text Analysis of Graduate Business Student Work Products}

Data for this study included eighteen assignments turned in by graduate students and twenty assignments turned in by undergraduate students. The input files created for analysis are MS Excel files. The authors had to cut each answer from MS Word files submitted by students and paste it into a row in a MS Excel file, a format used by this text analysis software product. This provided ample opportunity to read the communications provided by each student. Based upon this initial reading it appeared these graduate students created work products that contained more recognizable content from the reference materials provided than did the work products from the undergraduate students. Based upon this reading it was decided to analyze the graduate student work products first anticipating there would be a better match rate with the terms in the dictionaries and that new synonyms, in the words commonly used by graduate students, might be identified and added to 
the dictionary of synonyms. Why the graduate work products contained more relevant content than the undergraduate students is unknown and was unanticipated in advance. It could simply be a result of the selfselection process as to which subset of undergraduate students decides to go on to graduate school or perhaps because of the differences in the curricula between these particular graduate and undergraduate programs.

In the process of text analysis student works are taken as verbatims and matched against the terms and phrases in the library. Terms and phrases that match are 'extracted' for further processing. In this first step of the process 472 concepts were extracted from the 18 graduate student works. Extraction is the identification of concepts for which matches were found in one or more libraries and dictionaries used in the analysis.

In the second step, the concepts that pertain to the same topic are grouped together into categories. This study examined four categories; one for each of the institutional learning objectives. Table 1 exhibits each of the four institutional learning objectives assessed in this study and the set of extracted concepts that were assigned to this objective. The process of assigning concepts to categories is shared between the software that automatically assigns some, and the analyst that assigns some. The software only has the ability to associate extracted concepts to categories if the association was built into the libraries and the natural language processor. The more application specific are the concepts, the more the analyst needs to be involved in the assignment process for the early iterations of analysis. Once the associations have been programmed then the assignment will become more automated. The student work in which each extracted concept appears is retained by the software package and displayed for the analyst so there is a clear, visible mapping between student works, extracted concepts, and assigned categories. A clear, visible mapping adds transparency to assessment processes. This iterative process of engaging a human assessor who then adds content and associations to the dictionaries is how the library improves its ability 
to identify relevant content. It is in spirit a similar process as to how manual rubrics are improved over time.

In this study only 46 of the 472 concepts extracted from the works provided by graduate business students are directly related to the institutional learning goals. Most of the other concepts that were extracted were matches with other libraries already built into the software and were not relevant for this study. Some of the built-in libraries that are included in the software package are large and some matches are likely in almost any text that is analyzed.

\section{Assessment Results for Graduate Business Students}

Data were analyzed across the four institutional learning objectives and results are organized within these themes. Table 2 exhibits results for the four institutional learning objectives using work products from eighteen graduate students. The table indicates that 13 of 18 (72\%) students employed concepts from the references associated with 'Dimensions of Catholic Social Teaching' and 'Use of Their Gifts for the Service of Others and Benefit of Society'. The focus on the humanitarian relief exercise given to students was more strongly placed on these institutional learning objectives and correspondingly more terms and phrases from these references were built into the dictionaries which led to this result. The assessment conclusions of meeting, exceeding or not meeting expectations are completely arbitrary by the authors and used to provide an example.

Table 3 exhibits the breadth of coverage of the set of learning objectives in the graduate student work products. Four institutional learning objectives were assessed and this table indicates how many of the 18 students covered from none (0) up to four (4) of these learning objectives in their work product. It was very encouraging to see that 16 of 18 (89\%) of the student work products covered two or more institutional learning objectives. 


\section{Assessment Results for Undergraduate Business Students}

The same libraries, categories, extracted concepts assigned categories, and institutional learning objectives were used to analyze the undergraduate work products. There was no apparent reason to modify in advance what was done for analyzing the graduate level student work products. Graduate and undergraduate students were all given the same basic instructions and references.

Table 4 exhibits results for the four institutional learning objectives using work products from 20 undergraduate students. The table indicates that eight students (40\%) students employed concepts related to 'Dimensions of Catholic Social Teaching' and five students (5\%) incorporated concepts related to 'Use of Their Gifts for the Service of Others and Benefit of Society'. A comparison of the results presented in Tables 2 and 4 indicate that undergraduate students did not incorporate concepts from any of the institutional learning objectives at the same rate as did the graduate students. Why there was such a difference is unknown because this difference was not apparent or anticipated before the student works were assigned.

Table 5 exhibits the breadth of coverage of the set of learning objectives in the undergraduate student work products. Four institutional learning objectives were assessed and this table indicates how many of the 20 students covered $0-4$ of the learning objectives. Thirteen of 20 (65\%) of the undergraduate student work products covered less than two institutional learning objectives. Only 7 of 20 undergraduate students (35\%) provided evidence of incorporating content on two or more of the institutional learning objectives in their work products. A comparison with graduate student results presented in Table 3 indicates that undergraduate students did not communicate as much coverage of institutional learning objectives as did the graduate students. 


\section{Evidence of Coverage of Multiple Institutional LEARNING OBJECTIVES}

The IBM software product produces webmaps to graphically display the degree of coverage of pairs of categories which have been defined as institutional learning objectives for the purposes of this study. Coverage is defined as the number of student work products that were assessed to contain evidence of both learning objectives in a pair. Figure 2 displays the webmap for the graduate business students. The webmap displays four nodes as circles with labels; each node representing one of the four institutional learning objectives. The nodes are connected as pairs by lines that vary in their thickness. The thickness of each line represents the number of student works that were assessed and found to contain both learning objectives that are connected in the webmap. A legend is provided that indicates how the number of student works is represented by different line thicknesses.

For example in Figure 2 the learning objectives of 'Demonstrating Familiarity with Dimensions of Catholic Social Teaching' and 'Use Their Gifts for the Service of Others and Benefit Society' are connected with the thickest line. Both nodes are characterized with the largest circle corresponding to the most students $(n=13)$, displayed in the upper legend in Figure 2 and previously exhibited in Table 2 . The number of student work products that the thickest line represents is displayed in the lower legend, 9. Nine student work products were assessed to possess evidence of coverage of both of these institutional learning objectives. Nine students represent $50 \%$ of the 18 student works that were assessed and $69 \%$ (9 of 13) of the students that covered either of these learning objectives. In this exercise graduate business students made a strong connection between these two learning objectives.

Figure 3 displays the webmap for undergraduate business students. The label on each node has been shortened. As expected given the results exhibited in Table 4, this webmap exhibits smaller counts at each node and fewer student works that covered each pair of learning objectives. 
The most frequent pairs that were covered were ILG-Catholic Social Teaching and IL-KHE (Knowledge of the Human Experience), and ILKHE (Knowledge of the Human Experience) and ILG-Gifts for Service of Others. The undergraduate student works tended to put emphasis in their work products on the number of people suffering from hunger as evidence of their knowledge of the human experience.

Webmaps help to identify some of the instructional challenges. The challenge is to increase the number of student work products that cover multiple learning objectives. In the case of this study with four learning objectives, there are six binary pairs as represented in Figure 2. A comparison of webmaps over time can be used as a measure of how well a curriculum is helping student acquire the desired knowledge and skills.

\section{Conclusions}

The data from this study provides evidence that text analytics can be used for assessment of qualitative student works. Using the same assignment and 'rubric' comprised of terms, phrases, sematic meanings and synonyms, applied by an unbiased rater - the computer software, these results indicate that undergraduate work products did not provide as much content as graduate work products about specific institutional learning objectives. For reasons unknown at this time graduate students provided coverage of more learning objectives and a higher percentage of students covered provided content on each individual learning objective.

A possible conclusion is that separate libraries and dictionaries need to be created for use in assessing graduate and undergraduate work products. The alternative is to use the graduate results and libraries as a benchmark to work against for improving performance of undergraduate curricula. 


\section{IMPLICATIONS}

The purpose of assessing academic programs is to measure if students are graduating with the knowledge and skills the programs were designed to deliver. Results in this study suggest that perhaps the graduate business curriculum be reviewed to try and identify if there are some things that could be adopted by the undergraduate program to improve student performance.

Decisions need to be made as to the specific evidence students need to include in their work product to demonstrate they have achieved a certain level of learning regarding the learning objectives. Builders of text analysis packages need to decide which terms, phrases, and sematic meanings need to be matched to conclude a student work product provides evidence of having a grasp of the content they were asked to study. These terms, phrases and meaning do not need to be verbatim from reference materials but can be created by the instructors of the courses in which the content is studied. This is a process of continuous improvement that will improve the ability of a text analysis package to identify semantics that provide evidence of student learning on specific learning objectives. Each time an assessment is administered there will probably be some additions to custom-built dictionaries and libraries for different learning goals and objectives.

This process is the same with a manual rubric, but the difference is transparency and an ability to eliminate interrater reliability. When assessors use a manual rubric they can draw mental conclusions as to if the words and phrases in the student work products captured the concepts the students were asked to learn. Unfortunately, their conclusion can vary from student work product to student work product. Reliability is an issue when human judgement is involved. The automated process does not have the same intuition and ability, it only matches linguistic patterns. In this regard outside reviewers can look at the libraries, dictionaries, terms, semantic meanings, and synonyms to review and improve the process. Problems of inter-rater reliability regarding assessment of a student work 
are no longer an issue. An analogous problem emerges though when building the dictionaries and deciding on the most important terms, phrases and synonyms as well as assignment of extracted concepts to categories.

\section{REFERENCES}

AACSB International - The Association to Advance Collegiate Schools of Business. (2015). Eligibility procedures and accreditation standards for business accreditation. Tampa: AACSB International. Retrieved from www.aacsb.edu

Cambria, E., \& White, B. (2014, April 11). Jumping NLP curves: A review of natural language processing research. IEEE Computational Intelligence Magazine. doi:10.1109/MCI.2014.2307227

Canisius College. (n.d.). Goals and objectives. Retrieved from Canisius College: http://www.canisius.edu/about-canisius/mission/goalsobjectives/

Catholic Relief Services. (n.d.). Catholic Relief Services. Retrieved from CRS.org: http://www.crs.org/

Catholic Relief Services. (n.d.). One human family, food for all. Retrieved from CRS.org: https://www.youtube.com/watch?feature=player_ embedded $\& v=$ qhU5JEd $-X R o$

Catholic Relief Services. (n.d.). Pope Francis announces global campaign against hunger. Retrieved from CRS.org: https:/www.youtube.com/ watch?feature=player_embedded $\& v=$ A-sY_Olwkio

Catholic Relief Services. (n.d.). Pope Francis on caritas food for all week of action. Retrieved from CRS.org: https://www.youtube.com/watch? feature=player_embedded $\& v=5 \mathrm{~W} 5 \mathrm{pYudNeQY}$

Catholic Relief Services. (n.d.). Quotes on poverty and hunger. Retrieved from CRS.org: http://resources.crs.org/wp-content/uploads/2015/01/ Quotes-on-Poverty-and-Hunger.pdf 
Center for Excellence in Learning and Teaching. (n.d.). Revised bloom's taxonomy. Retrieved from http://www.celt.iastate.edu/teachingresources/effective-practice/revised-blooms-taxonomy/

IBM SPSS. (2010). Text analytics for surveys 4.0. SPSS Inc., an IBM Company.

Kaplan, J. J., Haudek, K. C., Ha, M., Rogness, N., \& Fisher, D. G. (2014). Using lexical analysis software to assess student writing in statistics. Technology Innovations in Statistics Education, 8(1). Retrieved from https://escholarship.org/uc/item/57r90703

Kelley, C., Tong, P., \& Choi, B.-J. (2010). A review of assessment of student learning programs at AACSB schools: A dean's perspective. Fournal of Education for Business, 85, 299-306. doi:10.1080/08832320903449519

Middle States Commission on Higher Education. (2015). Standards for accreditation and requirements of affiliation, thirteenth edition. Philadelphia: Middle States Commission on Higher Education.

$\mathrm{Xu}$, Y., \& Reynolds, N. (2012, August). Using text mining techniques to analyze students' written responses to a teacher leadership dilemma. International Journal of Computer Theory and Engineering, 4(4), pp. 575-578.

Yu, C. H. (2009). Merits and characteristics of text mining. Retrieved from Creative Widom: http://creative-wisdom.com/computer/sas/ text_mining.pdf

Yu, C. H., Jannasch-Pennell, A., \& DiGangi, S. (2011, May). Compatibility between text mining and qualitative research in the perspectives of grounded theory, content analysis, and reliability. The Qualitative Report, 16(3), 730-744. Retrieved from http://www.nova.edu/ssss/QR/ QR16-3/yu.pdf

\section{Citation Information}

Guy H. Gessner, and Karen M. Kutt-Doner. "Using Text Analysis to Assess Qualitative Student Works, Deal with Inter-rater Reliability, and Simultaneously Comply with AACSB Standard 8 and Middle States 
74 The BRC Academy Journal of Education Vol. 5, No. 1

Standard V .” The BRC Academy fournal of Education 5, no. 1 (2016): 5374. http://dx.doi.org/10.15239/j.brcacadje.2016.05.01.ja03.

\section{Web APPEndix}

A web appendix for this paper is available at:

http://dx.doi.org/10.15239/j.brcacadje.2016.05.01.wa03 